\title{
Comparative Ability of Six Fungicides to Inhibit Development of Phytophthora Gummosis on Citrus
}

\author{
M. E. Matheron, Extension Plant Pathologist and Research Scientist, and M. Porchas, Research Specialist, Uni- \\ versity of Arizona, Yuma Agricultural Center, Yuma 85364
}

\section{ABSTRACT}

Matheron, M. E., and Porchas, M. 2002. Comparative ability of six fungicides to inhibit development of Phytophthora gummosis on citrus. Plant Dis. 86:687-690.

The activity of the registered fungicides fosetyl-Al and metalaxyl (subsequently replaced with mefenoxam by the manufacturer) was compared with other potentially useful compounds, azoxystrobin, dimethomorph, fluazinam, and zoxamide, for suppression of canker development on citrus bark after inoculation with Phytophthora citrophthora or P. nicotianae. The number of sweet orange trees on which cankers developed after inoculation with P. citrophthora and the average size of cankers when present were lower on plants treated with dimethomorph, fosetyl$\mathrm{Al}$, or metalaxyl compared with nontreated trees and those treated with azoxystrobin or fluazinam. When bark removed from treated trees was inoculated with $P$. citrophthora on the cambium surface at 5, 30, or 60 days after treatment (DAT), inhibition of lesion development on bark strips treated with dimethomorph, fosetyl-Al, or metalaxyl was significantly greater than that detected on bark treated with azoxystrobin, fluazinam, or zoxamide. When inoculated with $P$. nicotianae at 5 or 30 DAT, reduction of lesion size on bark strips treated with dimethomorph, fosetyl-Al, or metalaxyl was significantly greater than that detected on bark treated with azoxystrobin or fluazinam. Inhibition of lesion development by zoxamide was significantly less than that observed with metalaxyl at 5 DAT on bark inoculated with P. nicotianae; however, at 30, 60 , and 90 DAT there was no significant difference in the performance of either fungicide. Reduction of lesion growth on the cambium surface compared with outer bark surface, when inoculated with $P$. citrophthora, did not differ significantly from 5 to 30 DAT for bark tissue treated with azoxystrobin, dimethomorph, fosetyl-Al, or metalaxyl. Among the nonregistered fungicides tested, dimethomorph provided the best level of Phytophthora gummosis control on citrus.

Phytophthora gummosis is an important disease of citrus trees (9). Phytophthora citrophthora and $P$. nicotianae (=P. parasitica) are cited as causal agents of gummosis in the United States; however, $P$. nicotianae is the primary pathogen on citrus in Florida (19) and Texas (17), whereas both species are important causes of disease in Arizona (15) and California (10). Losses attributable to Phytophthora gummosis and root rot have been reduced through the use of the systemic fungicides fosetyl-Al (Aliette, Aventis Crop Science, Research Triangle Park, NC) and metalaxyl (Ridomil, Syngenta Crop Protection, Greensboro, NC) $(4,7,16)$. Recently, the manufacturer replaced metalaxyl with mefenoxam (trade name Ridomil Gold). Mefenoxam is the active enantiomer of the fungicide metalaxyl and is applied in a similar manner as metalaxyl, except at lower rates of manufactured product. Label rates in the United States for application as a trunk spray to combat Phytophthora

Corresponding author: M. E. Matheron

E-mail: matheron@ag.arizona.edu

Accepted for publication 7 February 2002.

Publication no. D-2002-0401-01R

(C) 2002 The American Phytopathological Society gummosis are 48 to $96 \mathrm{~g}$ of fosetyl-Al or $40 \mathrm{~g}$ of mefenoxam ( $80 \mathrm{~g}$ of metalaxyl) per liter of spray solution.

Several other chemistries, including azoxystrobin (Abound, Syngenta Crop Protection) (8), dimethomorph (Acrobat, BASF Corporation, Research Triangle Park, NC) $(2,6,11)$, fluazinam (Syngenta Crop Protection) $(5,20)$, and zoxamide (Dow Agrosciences, Indianapolis, IN) (1), have activity against some species of Phytophthora or other oomycete organisms and the diseases they cause on crops other than citrus. The comparative activity of azoxystrobin, dimethomorph, fluazinam, fosetyl-Al, and metalaxyl on the growth, sporulation, and zoospore cyst germination of $P$. citrophthora and $P$. nicotianae has been determined in the laboratory (13). The objective of these investigations was to evaluate the ability of each of these compounds to suppress development of lesions on citrus bark inoculated with $P$. citrophthora and $P$. nicotianae. Zoxamide, which was not available for testing in our earlier laboratory studies (13), was included as well.

\section{MATERIALS AND METHODS}

Fungi and fungicides. One isolate each of $P$. citrophthora (C492S) and P. nicotianae $(\mathrm{C} 491 \mathrm{~S})$ was used in these studies, and both pathogens originated from soil within citrus orchards in Arizona. The following formulations of fungicides were used in these investigations: azoxystrobin (Abound 80WG), dimethomorph (Acrobat 50WP), fluazinam (Fluazinam 50WP), fosetyl-Al (Aliette 80WDG), metalaxyl (Ridomil 2E), and zoxamide (RH-7281 2F).

Tree trunk inoculation. Trunks of 2year-old Pineapple sweet orange trees (Citrus sinensis) growing in 3.8-liter pots in the greenhouse were painted with an aqueous solution of one of the following concentrations of active ingredients of each fungicide: metalaxyl at $60 \mathrm{~g} / \mathrm{liter}$; azoxystrobin, dimethomorph, fluazinam, or fosetyl-Al at $100 \mathrm{~g} /$ liter. Each fungicide was applied to trunks with a 2.5 -cm-wide disposable foam paintbrush and allowed to dry with trees lying horizontally to avoid dripping into the potting mix. At 3 and 33 days after treatment (DAT), a circular area of the outermost layer of bark tissue was removed from the trunk of sweet orange trees with a 5-mm-diameter cork borer. A 5-mm-diameter agar disk containing mycelium from an actively growing 7-day-old culture of $P$. citrophthora on V8 juice agar (V8A) (13), grown at $24^{\circ} \mathrm{C}$ in darkness, was placed onto the wound on each citrus tree trunk and secured in place with plastic tape. Plants were placed into large clear plastic bags to provide a humid environment favorable for infection and incubated at $21^{\circ} \mathrm{C}$ in an illuminated growth chamber under a photosynthetic photon flux density of 53 to $74 \mu \mathrm{E} \cdot \mathrm{m}^{-2} \cdot \mathrm{s}^{-1}$ with a $12-\mathrm{h}$ photoperiod for 2 weeks. Disease incidence and severity were assessed by noting the presence or absence of a trunk canker and measuring the length of canker that formed at the inoculation site.

Each treatment consisted of five replicate trees. Control trees were not treated with a fungicide. The outer epidermal layer of bark was removed to simulate injury that can often occur on citrus tree trunks.

Fungicide activity and persistence in citrus bark. In a 30-year-old high-density planting of Orlando tangelo trees (Citrus reticulata $\times C$. paradisi), a $25-\mathrm{cm}$ section of trunk on each of six trees was treated with an aqueous solution of one of the following concentrations of active ingredients of each fungicide: metalaxyl at 60 g/liter; azoxystrobin, dimethomorph, fluazinam, fosetyl-Al, or zoxamide at 100 $\mathrm{g} /$ liter. Each fungicide was applied to the tree bark with a 5.0-cm-wide disposable paintbrush. Control trees received no fungicide treatment. All treatments within the 
tangelo planting were arranged in a randomized complete block design. At 5, 30, 60 , and 90 DAT, a $20-\mathrm{cm}-$ long $\times 1.5-\mathrm{cm}-$ wide vertical strip of bark was removed from within the treated section of bark on each tree. Each bark strip was cut in half, then each piece was inoculated on the cambium side with a 5-mm-diameter agar disk containing mycelium from an actively growing 7-day-old culture of P. citrophthora or P. nicotianae on V8A. Inoculated bark strips were incubated in moist chambers for 5 days at $24^{\circ} \mathrm{C}$, after which the length of resulting lesions was recorded. Moist chambers were prepared by placing three layers of paper towels in each of several square plastic boxes $20 \mathrm{~cm}$ wide $x$ $5 \mathrm{~cm}$ high, then saturating the paper towels with water.

After inoculated bark strips were placed in each container, a lid was affixed and maintained for the duration of the experi- ment. No significant contamination problems occurred in this experiment.

In a second study, bark strips were collected at 5 and 30 DAT as described earlier. Each bark strip was cut in half, then one of the segments was inoculated on the cambium and the other on the outer bark surface with a 5-mm-diameter agar disk containing mycelium from an actively growing 7-day-old culture of $P$. citrophthora on V8A, as described earlier. Inoculated bark strips were incubated in moist chambers for 5 days at $24^{\circ} \mathrm{C}$, after which the length of resulting lesions was recorded.

Analysis of data. Each experiment in these investigations was conducted twice. Data from repeated experiments were combined for analysis since variances between experiments were homogeneous. Data were subjected to analysis of variance and means compared and separated at $\alpha=0.05$ according to the Duncan-

Table 1. Effect of fungicides applied to stems of 2-year-old sweet orange trees on subsequent development of cankers after inoculation with Phytophthora citrophthor ${ }^{\mathrm{z}}$

\begin{tabular}{lcccrcc}
\hline & & \multicolumn{2}{c}{ Trees with stem canker } & & \multicolumn{2}{c}{ Length of canker $(\mathbf{m m})$} \\
\cline { 6 - 7 } Treatment & Rate (g a.i./liter) & 3 DAT & 33 DAT & & 3 DAT & 33 DAT \\
\hline Metalaxyl & 60 & 1 & 1 & & $0.1 \mathrm{a}$ & $0.3 \mathrm{a}$ \\
Dimethomorph & 100 & 2 & 1 & & $0.2 \mathrm{a}$ & $0.1 \mathrm{a}$ \\
Fosetyl-Al & 100 & 2 & 1 & & $0.5 \mathrm{a}$ & $0.6 \mathrm{a}$ \\
Fluazinam & 100 & 9 & 10 & & $7.7 \mathrm{~b}$ & $8.7 \mathrm{bc}$ \\
Azoxystrobin & 100 & 9 & 7 & & $11.1 \mathrm{~b}$ & $5.7 \mathrm{~b}$ \\
Nontreated control & $\ldots$ & 10 & 10 & & $11.6 \mathrm{~b}$ & $9.2 \mathrm{c}$ \\
\hline
\end{tabular}

${ }^{\mathrm{z}}$ Plants were inoculated 3 and 33 days after treatment (DAT) with one of the test fungicides. Disease incidence and severity were assessed 2 weeks after inoculation. Each value is the mean of 10 replicate sweet orange plants from two runs of this trial. Numbers in each column followed by a different letter are significantly different $(P<0.05)$ according to the Duncan-Waller $k$-ratio least significant difference (LSD) test.

Table 2. Inhibition of lesion development after application of fungicides to outer bark surface of tangelo tree trunks and subsequent inoculation of cambium with Phytophthora citrophthora or $P$. nicotianae $^{\mathrm{y}}$

\begin{tabular}{|c|c|c|c|c|c|}
\hline \multirow[b]{2}{*}{ Treatment } & \multirow[b]{2}{*}{ Rate (g a.i./liter) } & \multicolumn{4}{|c|}{ Percent inhibition of lesion development ${ }^{\mathrm{z}}$} \\
\hline & & 5 DAT & 30 DAT & 60 DAT & 90 DAT \\
\hline \multicolumn{6}{|c|}{ Phytophthora citrophthora } \\
\hline Fosetyl-Al & 100 & $94 \mathrm{c}$ & $82 \mathrm{c}$ & $68 \mathrm{c}$ & $39 \mathrm{bc}$ \\
\hline Metalaxyl & 60 & $88 \mathrm{c}$ & $82 \mathrm{c}$ & $66 \mathrm{c}$ & $53 \mathrm{c}$ \\
\hline Dimethomorph & 100 & $78 \mathrm{c}$ & $60 \mathrm{~b}$ & $46 \mathrm{~b}$ & $42 \mathrm{bc}$ \\
\hline Azoxystrobin & 100 & $19 \mathrm{~b}$ & $14 \mathrm{a}$ & $24 \mathrm{a}$ & $17 \mathrm{ab}$ \\
\hline Zoxamide & 100 & $3 a b$ & $24 \mathrm{a}$ & $14 \mathrm{a}$ & $31 \mathrm{abc}$ \\
\hline Fluazinam & 100 & $0 \mathrm{a}$ & $7 \mathrm{a}$ & $27 \mathrm{a}$ & $8 \mathrm{a}$ \\
\hline \multicolumn{6}{|c|}{ Phytophthora nicotianae } \\
\hline Metalaxyl & 60 & $94 \mathrm{~d}$ & $83 \mathrm{~b}$ & $72 \mathrm{c}$ & $74 \mathrm{c}$ \\
\hline Fosetyl-Al & 100 & $87 \mathrm{~d}$ & $83 \mathrm{~b}$ & $55 \mathrm{bc}$ & $31 \mathrm{a}$ \\
\hline Dimethomorph & 100 & $57 \mathrm{c}$ & $74 \mathrm{~b}$ & $59 \mathrm{bc}$ & $41 \mathrm{ab}$ \\
\hline Zoxamide & 100 & $42 \mathrm{bc}$ & $66 \mathrm{~b}$ & $50 \mathrm{bc}$ & $65 \mathrm{bc}$ \\
\hline Azoxystrobin & 100 & $25 \mathrm{ab}$ & $26 \mathrm{a}$ & $35 \mathrm{ab}$ & $36 \mathrm{a}$ \\
\hline Fluazinam & 100 & $14 \mathrm{a}$ & $24 \mathrm{a}$ & $20 \mathrm{a}$ & $19 \mathrm{a}$ \\
\hline
\end{tabular}

${ }^{\mathrm{y}}$ Each fungicide was applied to a $25-\mathrm{cm}$ section of trunk on each of six Orlando tangelo trees. At 5 , 30,60 , and 90 days after treatment (DAT), a $20-\mathrm{cm}$-long $\times 1.5$-cm-wide strip of bark was removed from each tree in the experiment. Each bark strip was cut in half, then each segment was inoculated on the cambium side with a mycelial disk of $P$. citrophthora or $P$. nicotianae and incubated in a moist chamber for 5 days at $24^{\circ} \mathrm{C}$.

${ }^{\mathrm{z}}$ The percent inhibition of lesion development on treated compared with nontreated bark was determined 5 days after inoculation. This experiment was conducted twice, so that each value is the mean of 12 replicate Orlando tangelo trees. The average lengths of lesions developing on the cambium of nontreated bark tissue inoculated with P. citrophthora and P. nicotianae were 25 and 15 $\mathrm{mm}$, respectively. For each pathogen, numbers in each column followed by a different letter are significantly different $(P<0.05)$ according to the Duncan-Waller $k$-ratio least significant difference (LSD) test.

Waller $k$-ratio least significant difference (LSD) test.

\section{RESULTS}

Tree trunk inoculation. The number of sweet orange trees on which cankers developed after inoculation with $P$. citrophthora as well as the average size of cankers when present was lower on plants treated with dimethomorph and fosetyl-Al at $100 \mathrm{~g} /$ liter or metalaxyl at $60 \mathrm{~g} /$ liter when compared with nontreated trees and those treated with azoxystrobin and fluazinam at $100 \mathrm{~g} /$ liter (Table 1 ). The activity of dimethomorph, fosetyl-Al, and metalaxyl persisted in trees inoculated with the pathogen 33 DAT with each fungicide.

Fungicide activity and persistence in citrus bark. When inoculated with $P$. citrophthora at 5,30, or 60 DAT, inhibition of lesion development on bark strips treated with dimethomorph and fosetyl-Al at $100 \mathrm{~g} /$ liter or metalaxyl at $60 \mathrm{~g} /$ liter was significantly greater than that detected on bark treated with azoxystrobin, fluazinam, or zoxamide at $100 \mathrm{~g} / \mathrm{liter}$ (Table 2). By 90 DAT, differences in inhibition of lesion development among treatments became less pronounced, although the activity of dimethomorph, fosetyl-Al, and metalaxyl was still significantly greater than that of fluazinam.

When inoculated with $P$. nicotianae at 5 or 30 DAT, inhibition of lesion development on bark strips treated with dimethomorph, fosetyl-Al, or metalaxyl was significantly greater than that detected on bark treated with azoxystrobin or fluazinam (Table 2). At 60 DAT, lesion inhibition was still significantly greater on bark treated with dimethomorph, fosetyl-Al, or metalaxyl compared with fluazinam. By 90 DAT, lesion inhibition by metalaxyl was significantly greater than that by azoxystrobin, dimethomorph, fluazinam, or fosetyl-Al. The activity of zoxamide was significantly less than that of metalaxyl at 5 DAT; however, at 30,60, and 90 DAT there was no significant difference in the performance of either fungicide. The average lengths of lesions developing on the cambium of nontreated bark tissue inoculated with $P$. citrophthora and $P$. nicotianae were 25 and $15 \mathrm{~mm}$, respectively.

The percent reduction of lesion growth when either the inner or outer bark surface was inoculated with $P$. citrophthora did not differ significantly at 5 or 30 DAT for bark tissue treated with azoxystrobin, dimethomorph, fosetyl-Al, or metalaxyl (Table 3). The average lengths of lesions developing on nontreated cambium and outer bark tissue inoculated with $P$. citrophthora were 28 and $18 \mathrm{~mm}$, respectively.

\section{DISCUSSION}

The results of these investigations agree with previous work showing that metalaxyl applied as a trunk paint is highly effective for controlling Phytophthora infection on 
citrus tree trunks $(3,4,7,12)$. Trunk application of metalaxyl for management of Phytophthora gummosis of citrus is superior to soil drench treatments, as previous studies have shown that no fungitoxic activity was detected in trunk bark after a soil drench application of the fungicide $(3,4,18)$. As noted earlier (12), when applied directly to citrus bark tissue, fosetyl-Al was as effective as metalaxyl for inhibiting growth of lesions after inoculation with $P$. citrophthora or $P$. nicotianae. Some investigators have reported inconsistent results with fosetyl-Al on citrus $(3,4,18)$, perhaps due to methods used to detect activity, variable uptake by different tissues within the same Citrus sp., or differences in uptake among Citrus sp. Metalaxyl (since replaced with mefenoxam) and fosetyl-Al continue to be effective and important chemical management tools for Phytophthora gummosis.

Of the four other fungicides evaluated in these studies, dimethomorph generally performed as well as fosetyl-Al and metalaxyl with respect to suppressing lesion development on sweet orange trees inoculated with $P$. citrophthora and on tangelo bark tissue when inoculated with $P$. citrophthora or $P$. nicotianae. Recently, dimethomorph also was shown to be as effective as metalaxyl in suppressing development of cankers on chile pepper plants after inoculation with $P$. capsici (14). Zoxamide was able to partially suppress lesion formation on tangelo bark inoculated with $P$. nicotianae, but not with $P$. citrophthora, whereas azoxystrobin and fluazinam had no significant impact on lesion suppression in the presence of either pathogen.

Previous research revealed that mycelial growth of $P$. citrophthora and $P$. nicotianae on corn meal agar was more sensitive to dimethomorph, fosetyl-Al, and metalaxyl at $1,000 \mu \mathrm{g} / \mathrm{ml}$ than to azoxystrobin and fluazinam at the same concentration (13). Fungicide performance, as measured by inhibition of lesion formation on sweet orange trees and tangelo bark treated with these compounds, generally is in agreement with earlier in vitro studies.

A high level of lesion suppression by dimethomorph, fosetyl-Al, and metalaxyl was observed when treated bark strips were inoculated with $P$. citrophthora on the cambium or on the outer bark surface, suggesting that each of these compounds was able to move from the application site on the outer bark to the cambium on the inner bark surface. On the other hand, lesion inhibition tended to be greater on the outer bark compared with the inner bark surface for azoxystrobin, fluazinam, and zoxamide, suggesting negligible systemic movement within citrus bark by these fungicides.

Among the nonregistered fungicides tested, dimethomorph provided the best level of Phytophthora gummosis control. We did not explore the effects of this compound on the root rot phase of Phytophthora on citrus; however, recent research demonstrated that survival of chile pepper plants in soil naturally infested with $P$. capsici and treated with dimethomorph at $100 \mu \mathrm{g} / \mathrm{ml}$ was equivalent to plants

Table 3. Comparison of the inhibitory effect of fungicides on lesion growth in cambium to that in outer bark tissues inoculated with Phytophthora citrophthora after application of compounds to Orlando tangelo trees ${ }^{\mathrm{y}}$

\begin{tabular}{lccc}
\hline & & \multicolumn{2}{c}{ Percent inhibition of canker development $\mathbf{z}^{\mathbf{z}}$} \\
\cline { 3 - 4 } Treatment & Rate (g a.i./liter) & 5 DAT & 30 DAT \\
\hline Cambium & & & \\
Fosetyl-Al & 100 & $94 \mathrm{~d}$ & $82 \mathrm{e}$ \\
Metalaxyl & 60 & $88 \mathrm{~d}$ & $82 \mathrm{e}$ \\
Dimethomorph & 100 & $78 \mathrm{~d}$ & $60 \mathrm{~cd}$ \\
Azoxystrobin & 100 & $19 \mathrm{bc}$ & $14 \mathrm{ab}$ \\
Zoxamide & 100 & $3 \mathrm{ab}$ & $24 \mathrm{ab}$ \\
Fluazinam & 100 & $0 \mathrm{a}$ & $7 \mathrm{a}$ \\
Outer bark & & & $78 \mathrm{de}$ \\
Fosetyl-Al & 100 & $83 \mathrm{~d}$ & $79 \mathrm{de}$ \\
Metalaxyl & 60 & $77 \mathrm{~d}$ & $78 \mathrm{de}$ \\
Dimethomorph & 100 & $21 \mathrm{c}$ & $18 \mathrm{ab}$ \\
Fluazinam & 100 & $16 \mathrm{abc}$ & $31 \mathrm{~b}$ \\
Azoxystrobin & 100 & $12 \mathrm{abc}$ & $56 \mathrm{c}$ \\
Zoxamide & 100 &
\end{tabular}

${ }^{y}$ Each fungicide was applied to a $25-\mathrm{cm}$ section of trunk on each of six Orlando tangelo trees. At 5 and 30 days after treatment (DAT), a 20 -cm-long $\times 1.5$-cm-wide strip of bark was removed from each tree in the experiment. Each bark strip was cut in half, then each piece was inoculated either on the cambium or outer surface with a mycelial disk of $P$. citrophthora and incubated in a moist chamber for 5 days at $24^{\circ} \mathrm{C}$.

${ }^{z}$ The percent inhibition of lesion development on treated compared with nontreated bark was determined 5 days after inoculation. This experiment was conducted twice, so that each value is the mean of 12 replicate Orlando tangelo trees. The average lengths of lesions developing on nontreated cambium and outer bark tissue inoculated with $P$. citrophthora were 28 and $18 \mathrm{~mm}$, respectively. For each column, numbers followed by a different letter are significantly different $(P$ $<0.05$ ) according to the Duncan-Waller $k$-ratio least significant difference (LSD) test.

grown in sterilized soil, whereas plants grown in nontreated soil were dead after 2 to 3 weeks (14).

\section{LITERATURE CITED}

1. Alexander, S. A., and Waldenmaier, C. M. 2000. Evaluation of fungicides for control of late blight in white potato, 1999. Fungic. Nematicide Tests 55:191.

2. Cohen, Y., Baider, A., and Cohen, B.-H. 1995. Dimethomorph activity against oomycete fungal plant pathogens. Phytopathology 85:1500-1506.

3. Davis, R. M. 1981. Phytophthora foot rot control with the systemic fungicides metalaxyl and fosetyl aluminum. Proc. Int. Soc. Citric. 1:349-351.

4. Davis, R. M. 1982. Control of Phytophthora root and foot rot of citrus with systemic fungicides metalaxyl and phosethyl aluminum. Plant Dis. 66:218-220.

5. Dowley, L. J., and O'Sullivan, E. 1995. Activity of fluazinam against late blight of potatoes. Irish J. Agric. Food Res. 34:33-37.

6. Dowley, L. J., and O'Sullivan, E. 1996. The effect of dimethomorph on the control of late blight of potatoes. Irish J. Agric. Food Res. 35:165-169.

7. Farih, A., Menge, J. A., Tsao, P. H., and Ohr, H. D. 1981. Metalaxyl and efosite aluminum for control of Phytophthora gummosis and root rot of citrus. Plant Dis. 65:654-657.

8. Gisi, U., Hermann, D., Ohl, L., and Steden, C. 1997. Sensitivity profiles of Mycosphaerella graminicola and Phytophthora infestans populations to different classes of fungicides. Pestic. Sci. 51:290-298.

9. Klotz, L. J. 1978. Fungal, bacterial, and nonparasitic diseases and injuries originating in the seedbed, and nursery orchard. Pages 1-66 in: The Citrus Industry. Vol. 4, Crop Protection. W. Reuther, E. C. Calavan, and G. F. Carman, eds. University of California Agricultural Sciences Publications, Richmond.

10. Klotz, L. J., DeWolfe, T. A., and Wong, P.-P 1958. Decay of fibrous roots of citrus. Phytopathology 48:616-622.

11. Marks, G. C., and Smith, I. W. 1990. Control of experimental Phytophthora cinnamomi stem infections of Rhododendron, Leucadendron, and Eucalyptus by dimethomorph, fosetyl-Al, and metalaxyl. Aust. J. Exp. Agric. 30:139-143.

12. Matheron, M. E., and Matejka, J. C. 1988 Persistence of systemic activity for fungicides applied to citrus trunks to control Phytophthora gummosis. Plant Dis. 72:170-174

13. Matheron, M. E., and Porchas, M. 2000. Impact of azoxystrobin, dimethomorph, fluazinam, fosetyl-Al, and metalaxyl on growth, sporulation, and zoospore cyst germination of three Phytophthora spp. Plant Dis. 84:454458.

14. Matheron, M. E., and Porchas, M. 2000. Comparison of five fungicides on development of root, crown, and fruit rot of chile pepper and recovery of Phytophthora capsici from soil. Plant Dis. 84:1038-1043.

15. Matheron, M. E., Porchas, M., and Matejka, J. C. 1997. Distribution and seasonal population dynamics of Phytophthora citrophthora and $P$. parasitica in Arizona citrus orchards and effect of fungicides on tree health. Plant Dis. 81:1384-1390.

16. Sandler, H. A., Timmer, L. W., Graham, J. H., and Zitko, S. E. 1989. Effect of fungicide applications on populations of Phytophthora parasitica on feeder root densities and fruit yields on citrus trees. Plant Dis. 73:902-906.

17. Timmer, L. W. 1973. Characteristics of Phytophthora isolates from Texas citrus orchards J. Rio Grande Valley Hortic. Soc. 27:44-48.

18. Timmer, L. W., and Castle, W. S. 1985. Effec- 
tiveness of metalaxyl and fosetyl-Al against Phytophthora parasitica on sweet orange. Plant Dis. 69:741-743.

19. Timmer, L. W., Menge, J. A., Zitko, S. E., Pond, E., Miller, S. A., and Johnson, E. L.
1993. Comparison of ELISA techniques and standard isolation methods for Phytophthora detection in citrus orchards in Florida and California. Plant Dis. 77:791-796.

20. Washington, W. S., Shanmuganathan, N., and
Forbes, C. 1992. Fungicide control of strawberry fruit rots, and the field occurrence of resistance to Botrytis cinerea to iprodione, benomyl and dichlofluanid. Crop Prot. 11:355360. 